\title{
Long-term Individual Dietary Surveys
}

\author{
BY GWENETH M. CHAPPELL \\ Household Science Department, Queen Elizabeth College, \\ University of London
}

(Received 18 March 1954-Revised 25 fuly 1955)

It is known that the amounts of food consumed by individual men vary from day to day and that this variation may be considerable. Literature shows that surveys of short duration cannot be relied on to give a true picture of the normal dietary pattern. Seven-day studies are commonly taken as sufficient, although Wait \& Roberts (1932), McHenry, Ferguson \& Gurland (I945) and Yudkin (I95 I) conclude that I week cannot be considered a long enough period to give an accurate assessment of the average intake of nutrients by the individual. The survey made by Roberts, Kerr $\&$ Ohlson (1948) of the food intake of older women lasted for 6 months, and this appears to be the longest period recorded.

In view of the sparsity of information on this subject it was decided to record for long periods the intakes of foods and nutrients in the normal diet of two healthy adults pursuing their customary occupations. 'Healthy' is taken, in this context, to mean freedom from any apparent symptoms or signs of illness or malnutrition, and the existence of a feeling of well-being, a steady body-weight, good physique and sufficient energy to perform the normal activities of the subjects concerned.

\section{EXPERIMENTAL}

\section{Duration of survey}

To obtain an estimate of the average intake the duration of any survey should be sufficient to reflect the normal dietary of the subject and, preferably, the effect on it of seasonal influence. For this reason one survey lasted 70 weeks and the other 13 . The longer one was divided into two periods of $6 \mathrm{I}$ weeks and 9 weeks. A break of 13 weeks during this survey was made to test the subject's reaction to freedom from weighing food. Food records were not obtained for weeks 10 and 14 in this study.

\section{Subject $A$}

Subjects

Subject $A$ was a female university lecturer, aged 34 . Her height was $175 \mathrm{~cm}$ and her weight $62 \mathrm{~kg}$ in 1949 ; her mean weight over the study period was $6 \mathrm{I} \mathrm{kg}$.

Activity. Her activity was subject to variation: during the term she travelled daily to London and worked in a university department housed on two floors; in the vacation she remained in the country, either to work at a desk for 2 or 3 consecutive weeks or to engage in gardening or household duties. Her average activity probably amounted to a little less than 'moderate activity'. 
Food preferences. She did not eat meat other than bacon, ham and poultry. She ate salads and vegetables in preference to other foods at all suitable meals, and at least one salad every day.

Tobacco and alcohol. She smoked daily about twenty cigarettes until January $195^{\circ}$, when the number was reduced to three or four. She took very little alcohol; the total intake during the survey was $13 \mathrm{oz}$. cider and $16.9 \mathrm{oz}$. wine.

Health. She had mild influenza, lasting 2 days, on one occasion and slight head colds.

Basal metabolism. Her basal metabolism (estimated by the Benedict-Roth apparatus) was $1300 \mathrm{Cal} . / 24 \mathrm{~h}$.

Dates of survey. Her survey lasted from ro July 1949 to I March $195^{1 .}$

\section{Subject $B$}

Subject B was the father of subject A and was chosen because he was in the $7^{\text {th }}$ decade and little is known of the dietary habits of elderly persons. His age was 66 years, his height $169 \mathrm{~cm}$ and his weight (constant throughout the study) Ior $\mathrm{kg}$. He was retired.

Activity. He undertook no strenuous activity but did some walking and nonstrenuous work each day and was probably more active than a man in a sedentary occupation.

Food preferences. He ate meat and found the cheese ration inadequate; he ate little raw fruit or salad vegetables.

Tobacco and alcohol. He smoked three or four cigarettes daily and took almost no alcohol; his total intake of alcohol during the survey was I6 oz. cider.

Health. His health was good.

Basal metabolism. His basal metabolism (calculated according to Robertson \& Reid, I952) was $\mathrm{I} 78 \mathrm{C} \mathrm{Cal./24} \mathrm{h}$.

Dates of survey. His survey lasted from Io July I949 to 8 October I 949.

\section{Both subjects}

Subjects A and B ate most of their meals together during the latter's survey, so that the weighed ingredients for cooked dishes sufficed for both surveys during this time.

Neither subject took any vitamin preparation. Subject A took one penicillin lozenge, but no other medicine.

Compared with the scale of body-weights for different heights prepared by the United States Public Health Service, subject A was I3\% underweight and subject B was $12 \%$ overweight.

\section{Experimental methods}

Recording of intakes. Foods eaten during the survey period were weighed on dietary balances reading to I $g$. Edible and inedible waste was weighed and a suitable deduction made. Foods consisting of dissimilar parts, e.g. lean and fat of meat and bacon, icing on cakes and pastry on fruit tarts, were divided before weighing and the weights of the parts were recorded. 
All dishes prepared at home were weighed before and after cooking, and all ingredients were weighed on a dietary balance before use. Portions of these foods consumed were converted to their component ingredients before entry into the log-book, allowance being made for changes in weight during cooking. Dried egg was entered as dry weight. Shell eggs represented those eaten whole and portions of them included in cooked dishes. Dried milk was recorded as dry weight and all types of milk were entered separately: fresh, evaporated unsweetened, condensed sweetened, whole and skim. Fat used for frying was weighed, and any remaining in the pan was reweighed so that the exact quantity and kind absorbed by the food was recorded. Food thus cooked was entered in the log-book as 'cooked without fat' and, before entry, the weight of fat absorbed was deducted from the weight of the serving of food. With the exception of salt, pepper, dried herbs, vinegar and water, all foods consumed were entered in the log-book. The number of foods listed during the survey was 490 , the greatest number for any one subject in any one week being 78 .

In restaurants, balances were used to weigh edible portions and plate waste. When puddings and cakes containing fat and fruit were eaten, an estimate of the proportion of these ingredients was appended to the recorded weight. On visits, the subjects received willing co-operation from friends who provided recipes and encouraged weighing.

Evaluation of nutrients. The tables used during the survey were: Nutritive Value of Wartime Foods (Medical Research Council: Accessory Food Factors Committee, I945), Chemical Composition of Foods (McCance \& Widdowson, 1942), Nutritive Value of Foodstuffs (War Office, AMD 5, 1945), Tables of Food Composition in Terms of Eleven Nutrients (United States Department of Agriculture, I945).

Special analyses of some foods were obtained through the Scientific Adviser's Division of the Ministry of Food.

Figures for vitamin $\mathrm{C}$ were taken from tables giving values for raw and cooked foods. It was assumed that $15 \%$ of the thiamine in flour was destroyed during cooking. No allowance was made for the destruction of thiamine in boiled and steamed flour products, since the only flour served in this way was in thin gravy and a Christmas pudding.

Other information recorded. Personal weighing was undertaken each week. Whenever possible, the same beam and platform balance was used at the same hour of the same day in every week. Clothing was weighed on a spring balance and its weight deducted from the clothed body-weight.

A diary of activities and weather conditions, a record of health and, for the female subject, menstrual periods were kept.

A statistical examination of the mean daily caloric intake has been made in order to determine the influence of varying conditions on the mean energy expenditure, but the results of this analysis are not included in this paper. The conclusions drawn may be summarized by saying that the energy output of subject A was increased in winter months, in very cold weather and by physical exercise. Menstruation had no apparent effect on energy expenditure, but since menstruation occurred in 3 weeks of hot weather, 4 of cold weather, 2 of inactivity and in each of the 6 weeks of extra activity, 
there may well have been conflicting influences on the body's energy requirement which resulted in one being masked by the other.

Food rationing. Changes in food rationing were responsible for alterations in the quantities of some foods available during the survey period.

\section{Recommended allowances}

The mean intake of each subject was compared with allowances recommended by the (U.S.A.) National Research Council (1948), the dietary standards of the Canadian Council on Nutrition (1950) and the nutritional requirements suggested by the British Medical Association (1950). These standards are hereinafter referred to as the N.R.C., C.C.N. and B.M.A. respectively.

The most appropriate categories for comparison for the female subject were thought to be as follows: N.R.C., moderately active; C.C.N., moderately active woman of I20 lb. body-weight; B.M.A., light work and travelling. The N.R.C. standard is probably in excess of the requirement of subject $\mathrm{A}$, but she was not sedentary, and comparison with standards for sedentary women was not considered justifiable. Furthermore, this subject weighed $6 \mathrm{I} \mathrm{kg}$ and the average woman quoted in N.R.C. tables weighs only $56 \mathrm{~kg}$.

In determining a standard for comparison in C.C.N. tables, it was necessary to select between body-weight groups of 120 and $140 \mathrm{lb}$. The mean weight of subject A was $\mathrm{r} 34 \mathrm{lb}$. Although it is nearer $\mathrm{r} 40$ than $120 \mathrm{lb}$., the latter was chosen to compensate, in part, for the fact that activity was thought to be less than moderate.

For the male subject, who was less active than subject $A$, comparison was made with N.R.C. recommendations for sedentary males and B.M.A. allowances for 'light work and travelling'. The mean body-weight of this subject was IOI $\mathrm{kg}$ or $224 \mathrm{lb}$., which undoubtedly increased his energy requirement above the level recommended for the 'average' man, but increasing age reduces the body's requirement. This factor will be discussed later.

The C.C.N. standard for sedentary males of $200 \mathrm{lb}$. body-weight, representing the upper limit of this scale, was used for comparison. The Canadian Council on Nutrition estimates that for every $10 \mathrm{lb}$. by which a person differs in weight from the average of his group, the needs for maintenance change by I Io Cal. Subject B would, therefore, require $3^{145} \mathrm{Cal}$., and comparison has also been made with this estimate.

\section{RESULTS}

Subject $A$

\section{Intake of calories and nutrients}

The mean daily intakes of calories and nutrients in each week of the survey are summarized in Table I. These figures are presented in a similar way to those recorded by other observers in 7 -day surveys. Table 2 shows the contributions made by fat, carbohydrate and protein to the total caloric intake. The mean weekly intake of certain foods is shown in Table 3 . 
Table I. Mean daily intake of calories and nutrients in each survey

\begin{tabular}{|c|c|c|c|c|c|c|}
\hline \multirow[b]{2}{*}{ Nutrient } & \multicolumn{3}{|c|}{ Subject A } & \multicolumn{3}{|c|}{ Subject B } \\
\hline & Mean & Range & $\begin{array}{l}\text { Percentage } \\
\text { standard } \\
\text { error }\end{array}$ & Mean & Range & $\begin{array}{c}\text { Percentage } \\
\text { standard } \\
\text { error }\end{array}$ \\
\hline Total protein (g) & $65 \cdot 8$ & $5 I \cdot 0-82 \cdot r$ & 10.0 & $98 \cdot 9$ & $88 \cdot 7-109 \cdot 4$ & $6 \cdot 8$ \\
\hline Animal protein (g) & $34 \cdot 1$ & $22 \cdot 8-44 \cdot 7$ & I $5 \cdot 4$ & $53 \cdot 8$ & $42 \cdot 6-64 \cdot 0$ & $12 \cdot 6$ \\
\hline Fat $(\mathrm{g})$ & $87 \cdot 7$ & $68 \cdot 8-106 \cdot 0$ & 10.5 & $12 I \cdot I$ & $97 \cdot 6-145 \cdot 6$ & 13.4 \\
\hline Carbohydrate (g) & $305 \cdot 8$ & $253 \cdot 9-369 \cdot 9$ & $7 \cdot 7$ & $400 \cdot 6$ & $328 \cdot 7-454 \cdot 0$ & $9 \cdot 5$ \\
\hline Calories (Cal.) & 2275 & $1874-265 I$ & $7 \cdot 6$ & 3089 & $2572-3520$ & $9 \cdot 1$ \\
\hline Calcium* (mg) & 1078 & $779-1422$ & I 3.5 & 1425 & $1241-1636$ & $9 \cdot 3$ \\
\hline Iron (mg) & $\mathrm{I} 2 \cdot 8$ & $8 \cdot 66-19 \cdot 29$ & 14.9 & I 5.79 & $12 \cdot 28-19 \cdot 6$ & II 7 \\
\hline Vitamin A (i.u.) & 2827 & $1242-4799$ & $24 \cdot 9$ & 3100 & $1762-6529$ & $13 \cdot 6$ \\
\hline Thiamine (mg) & $I \cdot I 9$ & $0.95^{-I} \cdot 5^{8}$ & $11 \cdot 9$ & $I \cdot 64$ & $I \cdot 43-I \cdot 92$ & $9 \cdot 8$ \\
\hline Riboflavin (mg) & $1 \cdot 60$ & $I \cdot 20-2 \cdot 10$ & I3. I & $\mathrm{I} \cdot 86$ & $I \cdot 59-2 \cdot 34$ & $13 \cdot 4$ \\
\hline Nicotinic acid (mg) & 10.08 & $6.94-15.05$ & 14.9 & 13.14 & $11 \cdot 23-18 \cdot 44$ & $14^{\circ} 0$ \\
\hline Vitamin C (mg) & 146 & $78-250$ & $24 \cdot 3$ & 104 & $73-132$ & $17 \cdot 0$ \\
\hline Vitamin D (i.u.) & I 89 & $34-657$ & $74 \cdot 9$ & 215 & $59-501$ & $75 \cdot 7$ \\
\hline
\end{tabular}

Table 2. Proportion of the total caloric intake supplied by protein, fat and carbohydrate and proportion of total protein derived from animal sources in each survey

Percentage of calories derived from

$\overbrace{\text { Fat } \quad \text { Carbohydrate Protein }}$

Subject $A$

Mean

Percentage standard error

Mean

Range

Percentage standard error

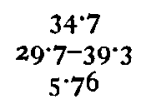
$53 \cdot 8$
$49^{\circ} 4^{-60} \cdot 4$
$3 \cdot 96$
$11 \cdot 6$
$9 \cdot 2-13^{\cdot 6}$
$7 \cdot 76$

Subject B

$35 \cdot 2$
$3 r \cdot 4-38 \cdot 6$
$5 \cdot 85$

Animal protein as percentage of total protein

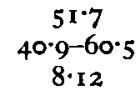

$\begin{array}{ccc}5 I \cdot 9 & 12 \cdot 8 & \\ 48 \cdot 3-55 \cdot 9 & I I \cdot 1-14 \cdot 9 & 48 \cdot 0-62 \cdot 3 \\ 4 \cdot 32 & 8 \cdot 67 & 7 \cdot 45\end{array}$

Table 3. Mean weekly intake of certain foods in each survey

Food

Milk (pt.)

Eggs (no.)

Cheese (oz.)

Meat (oz.)

Fish (oz.)

All fats (oz.)

Flour, cake, bread and wheat products (oz.)

Other cereals (oz.)

Potatoes (oz.)

Other root vegetables (oz.)

Green vegetables and salad plants (oz.)

Fruit, including tomatoes (oz.)

Sugar (oz.)

Honey, syrup, preserves (oz.)

Chocolate and sweets (oz.)

Ice cream (oz.)
Subject A Subject B (70-week period) (13-week period)

\begin{tabular}{|c|c|}
\hline 5.7 & $6 \cdot 4$ \\
\hline $3 \cdot I$ & $\mathrm{I} \cdot 4$ \\
\hline $1 \cdot 5$ & $8 \cdot 1$ \\
\hline 3.7 & $27 \cdot 6$ \\
\hline $\begin{array}{r}10.4 \\
8.2\end{array}$ & $\begin{array}{r}9.5 \\
11.8\end{array}$ \\
\hline $39^{\circ} \mathrm{I}$ & 84.5 \\
\hline $\begin{array}{r}4 \cdot 5 \\
64 \cdot 2\end{array}$ & $90 \circ 0$ \\
\hline 19.5 & $9 \cdot 8$ \\
\hline 40.4 & $19^{\circ} \mathrm{I}$ \\
\hline $69 \cdot 2$ & $39 \cdot 6$ \\
\hline $8 \cdot 2$ & 15.8 \\
\hline 6.4 & 6.7 \\
\hline $8 \cdot 6$ & 0.7 \\
\hline $5 \cdot 3$ & 3.8 \\
\hline
\end{tabular}


Protein. As subject A ate little meat, she obtained animal protein chiefly from fish and milk. There were only 7 weeks in the whole survey when less than 5 pt. milk were consumed, and on several occasions intake exceeded $7 \mathrm{pt}$.

Calcium. Intake was high, largely because milk was consumed liberally, though vegetables and canned fish added appreciable amounts to the daily total. No allowance has been made for calcium obtained from tap water, which, in London, is probably about $100 \mathrm{mg}$ daily (Widdowson \& McCance, 1943). It would increase the mean daily intake to about $1180 \mathrm{mg}$.

Iron. No allowance has been made for possible 'contamination' of foods by the use of iron utensils and vessels (Widdowson \& McCance, 1943), so that, as with calcium, intakes recorded in this survey may be regarded as minimal amounts.

Though the contribution of all fruits and vegetables to the total intake was considerable, individual foods supplying constant large amounts of iron were bread, breakfast cereals, potatoes, eggs and, in some weeks, chocolate.

Vitamin $A$. The usual assumption has been made that 3 i.u. carotene are equal in potency to I i.u. preformed vitamin A. Approximately $155^{\circ}$ i.u. preformed vitamin A were supplied daily by butter, margarine, milk and eggs. In addition, carotene was supplied in very large amounts by vegetables, e.g. 52,000 i.u. from carrots in one week.

Thiamine and riboflavin. Milk was the chief source of riboflavin. Potatoes and milk yielded approximately equal amounts of thiamine; there were occasional large additions from fish roes and peas.

Vitamin C. Values given for vitamin $\mathrm{C}$ intake allow for losses on cooking. The large amounts of fruit and vegetables consumed by subject $A$ resulted in a mean daily intake over the whole survey of $146 \mathrm{mg}$.

Vitamin $D$. This vitamin showed the largest weekly variation recorded in this study. Large amounts of it are usually obtained from foods consumed at comparatively infrequent intervals. Between $3^{8}$ and 657 i.u. were obtained in different weeks from margarine, a small amount from butter and eggs, about 70-100 i.u. from milk and, less frequently, large amounts from canned fish and herrings.

\section{Subject $B$}

The mean daily intakes of calories and nutrients are summarized in Table I. In Table 2 are shown the contributions made by protein, fat and carbohydrate to the total caloric intake. Despite the differences in the diet consumed by both subjects, mean values for fat, carbohydrate and protein differed by only $0.5, \mathrm{r} \cdot 9$ and $\mathrm{r} \cdot 2 \%$ respectively. The mean weekly intakes of certain foods are shown in Table 3 .

Protein. An average of $54.6 \%$ of the total protein intake was supplied by animal foods, a value only $0.5 \%$ larger than the percentage obtained by subject $\mathrm{A}$ in the 9 -week study and $2.9 \%$ larger than that obtained in the whole survey. This agreement is unexpected in view of the fact that subject $B$ took at least $20 \mathrm{oz}$. of meat, meat products and offal each week, as well as the full cheese ration and generous amounts of milk. In only one week were less than $5 \mathrm{pt}$. milk consumed, and in one week the ntake reached 9 . I pt. 
Calcium. Milk and bread together supplied from 700 to more than I I00 $\mathrm{mg}$ calcium/day. No allowance has been made for calcium supplied by tap water.

Iron. Bread was the chief source of iron, with meat, sausages, potatoes and vegetables supplying smaller amounts. Offal supplied occasional large quantities.

Vitamin A. Unlike subject A, subject B obtained most of his total intake as preformed vitamin $A$. In one week liver supplied 26,620 i.u. The mean percentage obtained as carotene was $12 \cdot 6$. For subject $B$ the variation of total intake of vitamin $A$ followed that of preformed vitamin $A$, whereas for subject $A$ it followed that of carotene.

Vitamins of the $B$ complex. These were supplied chiefly by bread, milk and potatoes. Cheese, meat, tongue and bacon supplied smaller amounts, and plums, peas and tomatoes also contributed to the total intake.

Vitamin $C$. This vitamin was derived chiefly from potatoes, which supplied more than $40 \mathrm{mg} /$ day.

Vitamin $D$. The intake again varied more than that of any other nutrient.

\section{Weight of food consumed}

For both subjects, the weight of food consumed each day was compared with the caloric intake; as was expected, there was no close relationship between these amounts. The mean daily weight of food eaten by subject $A$ was $62.5 \mathrm{oz}$. and by subject $B$ $66 \cdot 7$ oz. Corresponding caloric intakes were 2275 and 3089 Cal. Subject A obtained $36 \cdot 4 \mathrm{Cal} /$ /oz. food eaten and subject $\mathrm{B}, 46 \cdot 3 \mathrm{Cal}$. The difference is easily explained by the large proportion of fruit and vegetables in the diet of subject $\mathrm{A}$.

The total weight of food consumed in a year by subject $A$ was 0.62 ton; the weight which would presumably have been consumed by subject B ( 13 weeks' intake $\times 4$ ) was 0.67 ton.

\section{DISCUSSION}

In any dietary survey there are possible sources of error. Of these, the chief are the measurement of food intake, the use of tables of food composition to calculate nutrient intake and the shortness of the period of study. A reasonably accurate measurement of intake should be obtained if the subject weighs and records his diet carefully and procures recipes for composite cooked dishes or, as in this survey, uses dishes made from weighed ingredients.

In methods involving the use of food tables it is not possible to ensure that the calculated intake represents exactly the actual intake, on account of the variations in the composition of different samples of many kinds of food, and of the effect of different methods of cooking on the individual nutrients of foods.

Investigations by several workers (e.g. Bransby, Daubney \& King, 1948-9a, $b$; Widdowson \& McCance, 1943, I945; Tigerstedt, 1916) into the extent to which the use of food tables gives results that differ from those obtained by chemical analysis appear to suggest that accuracy is increased for individual diets when the period of study is prolonged. This increase in accuracy probably results from the tendency for the errors involved in the method of weighing foods and using food tables to cancel out, and 
from the better assessment of individual intake which is obtained from a greater number of results for each subject. The duration of any study should be sufficiently long to reflect the normal dietary pattern of the subject; the period required for this purpose in the present investigation will be discussed later.

Every effort was made to avoid inaccuracies in the calculation of nutrient intakes in the present survey, and it will be assumed that relative intakes of nutrients as between the two subjects and as between different periods for one subject are reasonably free from error.

\section{Variations in caloric intake}

One of the subjects in the 4-week study of Yudkin (195I) had a caloric intake $68 \%$ greater in the week of highest intake than in that of the lowest. Yudkin asks whether the degree of variation is the same for any one subject or whether it varies.

The percentage differences between extreme caloric intakes in periods of 4 consecutive weeks in the study of subject A ranged from $2 \cdot 3$ to $30^{\circ} 0$, and in the study of subject $B$ they ranged from $14 \cdot 0$ to $24^{\prime} \mathrm{I}$.

\section{Variation in vitamin $C$ intake}

Foods containing vitamin $\mathrm{C}$ in high concentration are frequently consumed irregularly. There is also a seasonal variation in the availability of those fruits and vegetables that are potent sources of vitamin $\mathrm{C}$ and in the vitamin $\mathrm{C}$ content of potatoes, which supply the greater proportion of ascorbic acid in many diets. The usual rise in the intake of vitamin $\mathrm{C}$ in the summer (Harris \& Olliver, I943; British Medical Association, 1950) was not shown by subject A, owing undoubtedly to the fact that her diet contained a high proportion of fruit and vegetables throughout the year.

\section{Variability of nutrient and caloric intake in subject $A$}

Standard errors for the weekly intake of the dietary constituents over the 70-week period of study are given in Table 4. An attempt will now be made to determine the length of survey period required to give estimates of the average intake for the individual with specified accuracy.

It must be remembered that the present findings derive from one subject only, so that the variability in other dietary studies of a similar kind might be very different (Yudkin, 1951). For this reason it is not possible to draw general conclusions as to the kind of sample required to provide an estimate of average intake with specified accuracy until the present results can be compared with those of other individual dietary studies.

In the second column of Table 4 the percentage standard errors are given for estimates of average daily intakes of calories and nutrients during a year. These values are based on values for I week selected at random.

Intakes of vitamins A, C and D are generally more variable than those of other nutrients because of irregular or seasonal consumption of foods that are potent sources of these vitamins. Since there is no reason to think that the dietary habits of this subject were exceptionally variable, it can be assumed that standard errors of $25 \%$ or 
Table 4. Subject A: percentage standard errors of average daily consumption of calories and nutrients estimated from a single period sampled at random within a year

\begin{tabular}{|c|c|c|c|c|c|c|}
\hline \multirow{2}{*}{ Nutrient } & \multicolumn{6}{|c|}{ Duration of sampling period (weeks) } \\
\hline & I & 2 & 4 & 6 & 8 & 12 \\
\hline Total protein & 10.0 & $8 \cdot 5$ & $7 \cdot 4$ & $6 \cdot 9$ & $6 \cdot 6$ & $6 \cdot 3$ \\
\hline Animal protein & 15.4 & $12 \cdot 6$ & 10.9 & $9 \cdot 8$ & $9 \cdot \mathbf{I}$ & $8 \cdot 1$ \\
\hline Fat & 10.5 & $8 \cdot 2$ & $6 \cdot 3$ & $5 \cdot 8$ & $5 \cdot 4$ & $5 \cdot 1$ \\
\hline Carbohydrate & $7 \cdot 7$ & $6 \cdot I$ & $4 \cdot 8$ & $4 \cdot 3$ & 4.0 & $3 \% 7$ \\
\hline Calories & $7 \cdot 6$ & $6 \cdot 1$ & $4 \cdot 8$ & $4 \cdot 3$ & $4 \cdot 0$ & $3 \cdot 8$ \\
\hline Calcium & 13.5 & $12 \cdot 6$ & II $\cdot 7$ & $11 \cdot 2$ & 10.7 & 10.1 \\
\hline Iron & 14.9 & $I I \cdot 6$ & 9.6 & 9.2 & $9 \cdot 0$ & 8.8 \\
\hline Vitamin A & 24.9 & $22 \cdot 6$ & $20 \cdot 2$ & 17.9 & 16.4 & $12 \cdot 5$ \\
\hline Thiamine & II.9 & 10.6 & $9 \cdot 9$ & $9 \cdot 8$ & 9.5 & $9 \cdot 2$ \\
\hline Riboflavin & $13 \cdot 1$ & $12 \cdot 2$ & $11 \cdot 8$ & $11 \cdot 4$ & $11 \cdot 2$ & 10.9 \\
\hline Nicotinic acid & 14.9 & 13.0 & $\mathrm{II} \cdot 5$ & $I I \cdot I$ & 10.7 & 10.7 \\
\hline Vitamin C & $24 \div 3$ & $18 \cdot 3$ & 13.7 & $12 \cdot 4$ & II 3 & 9.9 \\
\hline Vitamin D & 74.9 & 51.0 & $38 \cdot 0$ & $32 \cdot 0$ & $26 \cdot 0$ & $17 \cdot 3$ \\
\hline
\end{tabular}

more of the average are to be expected for intakes of these vitamins in dietary surveys lasting only $\mathrm{I}$ or 2 weeks. In the present survey, mean daily intakes of vitamin $D$ in adjacent weeks varied between 44 and 444 i.u. and 102 and 657 i.u.; intakes of vitamin A varied between 1895 and 2616 i.u. and 3093 and 4799 i.u.

For other nutrients the percentage standard error may be as great as 15 .

Reference to Table 4 shows that single sampling periods longer than I week may be expected to give rather more accurate estimates of the mean intake. For total protein, for example, the standard error of the mean intake estimated from a random sample of $I$ week is $10 \%$ of the mean; for a random sample of I month it is $7 \frac{1}{2} \%$ of the mean, and for a random sample of 3 months it is just over $6 \%$ of the mean. The increase in accuracy obtained by increasing the survey period beyond I week is not very large, because intakes in consecutive weeks are positively correlated. Thus, for example, when the intake in the Ist week of a sampled period is above the average for the year, the intake in the and week also tends to be above average.

More accurate estimates of mean intake can be obtained by taking records from a number of weeks selected independently at random than from a single period of the same total duration. If 12 weeks were sampled within I year, estimates of mean protein intake with the following percentage standard errors would be expected for the different subdivisions of the total period sampled:

Duration of sampling period (weeks)

No. of independent sampling periods

Percentage standard error of estimated mean protein intake

$\begin{array}{clllc}1 & 2 & 4 & 6 & 12 \\ 12 & 6 & 3 & 2 & 1 \\ 2 \cdot 9 & 3 \cdot 5 & 4 \cdot 3 & 4 \cdot 9 & 6.3\end{array}$

Since the variability between weekly intakes increases when the period from which they are selected is also increased, it is advantageous to divide the year into periods of equal length and to take one sample from each period.

Fig. I shows the relationship between the length of the period and the variability between weeks in that period for subject $A$. To obtain these values, the average over all the dietary constituents except vitamin $\mathrm{D}$ has been taken. 
It can be seen from this figure that if I week is sampled at random from within a period of 4 weeks, the sampling variance is $65 \%$ of the total variance within a year; if $\mathrm{I}$ week is sampled at random from within a period of 26 weeks, the sampling variance is $82 \%$ of the total variance within a year.

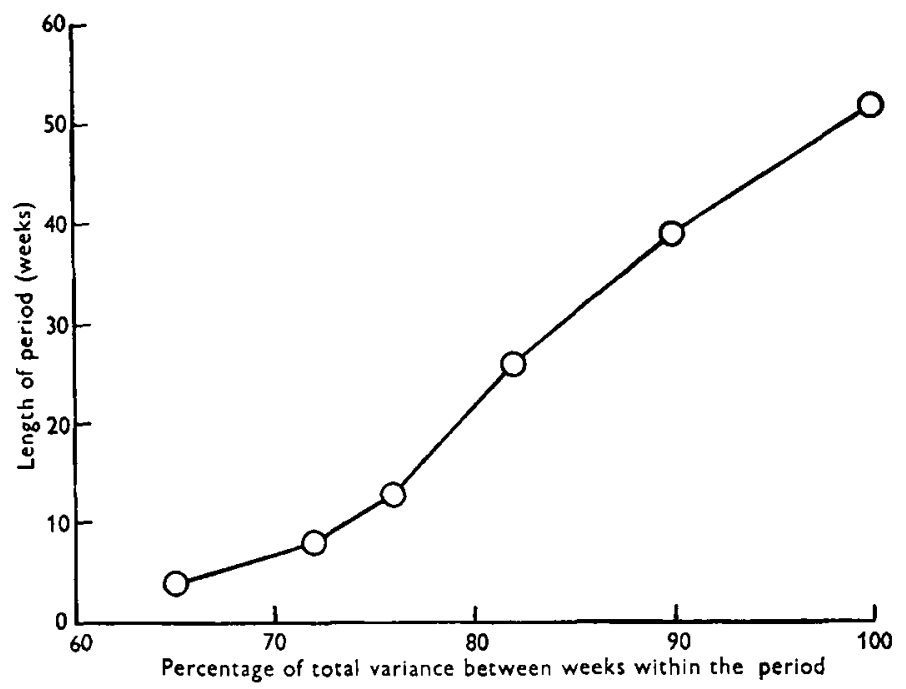

Fig. I. Subject A: percentage of total annual variance within periods of different lengths.

Returning to the examination of the total protein intake, it is of interest to select twelve I-week samples independently at random from within consecutive $\mathrm{I}$-month strata and to select six fortnightly samples independently at random from consecutive 2-month strata, and so forth. The standard errors of the estimates of the mean protein intake obtained are then as follows:

Duration of sampling period (weeks)

No. of independent sampling periods (chosen at random within strata)

Percentage standard error of estimated mean protein intake

$\begin{array}{ccccc}\text { I } & 2 & 4 & 6 & 12 \\ 12 & 6 & 3 & 2 & \text { I } \\ 2 \cdot 3 & 2 \cdot 9 & 3 \cdot 8 & 4 \cdot 4 & 6 \cdot 3\end{array}$

Comparison of these values with those given on p. $33^{1}$ shows that it is advantageous to subdivide the year into equal strata, but the advantage decreases as the number of strata is reduced. A systematic selection of individual sampling periods, e.g. every $4^{\text {th }}$ week or every $4^{\text {th }}$ fortnight in the present study, may produce estimates somewhat more accurate than those from stratified random samples, but it is difficult to assess the increase in accuracy obtained by this method of systematic sampling.

A practical consideration in dietary surveys is the determination of the number of weeks' sampling needed to attain a specified level of accuracy. If an estimate of the total protein intake with a standard error of $5 \%$ is required, there is only one chance in twenty of this estimate differing from the true mean value by more than $10 \%$.

From the information given above on the variability of the data it can be deduced that estimates of about this accuracy will be provided by a systematic sample consisting of three I-week periods at intervals of 4 months or by a systematic sample of 
two periods of a fortnight separated by an interval of 6 months. A single period of as much as 12 weeks' duration does not provide such an accurate estimate (see p. 332).

Calculations could be made for each separate nutrient, but an approximation for general application can be obtained by using an average estimate of the relative variability between sampling periods of different durations based on the intake of calories and all nutrients. This approximation shows that a systematic sample of three I-week periods (or 4 single weeks or 3 fortnights, selected independently at random) should provide estimates of average intake over the year with percentage standard errors about half those for a I-week survey. In the present survey such samples would estimate the mean intake of calories and eight nutrients with standard errors of $\pm 8 \%$ or less. The estimate for vitamin D would still have a standard error of $\pm 35 \%$.

The foregoing discussion indicates that the total survey period required to provide estimates of mean dietary intakes of specified accuracy is reduced if the period sampled is subdivided and a systematic or stratified random sample is taken. One consideration must, however, be borne in mind, namely, that the technique of weighing or recording intake may consciously or subconsciously affect the dietary habits of the subject. Any deviation from normal habits may be thought to be more likely to occur in a short survey. The present data provide no evidence of bias in the initial recording, and for none of the nutrients were the intakes recorded in the ist week significantly different from the average intakes over the whole period. This finding suggests that appetite was not unduly altered by a first approach to survey technique.

The numerical methods used in estimating the sampling errors discussed in this section are set out more fully by Church \& Lipton (I955), who also give a more general treatment of the sampling problems involved.

\section{Calories}

Relation of intake to recommended allowances

The mean daily intakes of calories and nutrients of both subjects are compared with recommended allowances in Table 5. If the weight is to remain constant the intake of calories should correspond exactly to the requirement. It is difficult to assess the individual caloric requirement exactly; calculations of basal metabolism, based on height and weight, provide some indication of it but do not reveal deviations from the accepted mean. Direct measurement of the oxygen consumption under basal conditions is a more satisfactory way of estimating basal metabolism. The use of recommended allowances of calories for persons of the same age, sex and degree of activity provides at best only an approximate estimate of individual requirements, which vary according to surface area, basal metabolism, age, muscular efficiency and other factors. The factorial method of estimating individual energy expenditure is also inaccurate.

Subject $A$. The basal metabolism of this subject as determined by the BenedictRoth apparatus was $1300 \mathrm{Cal} . / 24 \mathrm{~h}$. This value is below her calculated basal metabolism and serves to illustrate the degree of error introduced into estimates of energy expenditure by the use of calculated values. 
Table 5. Mean daily intake of calories and nutrients as a percentage of N.R.C., B.M.A. and C.C.N. standards (see p. 326)

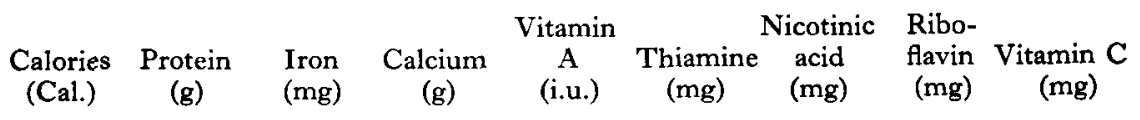

B.M.A. standard for light work and travelling

Mean intake in 70 weeks, as

2250

percentage of standard

N.R.C. standard for moder-

ately active woman

Mean intake in 70 weeks, as

percentage of standard

C.C.N. standard for moder-
ately active woman, $120 \mathrm{lb}$.

ately active woman, $120 \mathrm{lb}$.
Mean intake in 70 weeks, as

percentage of standard

Subject A

B.M.A. standard for light

IOI'I

$66 \quad \mathrm{I} 2 \cdot 0 \quad 0$

$\begin{array}{llllll}8 & 2500 & 0.9 & 9.0 & I .4 & 20\end{array}$

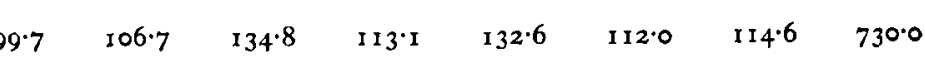

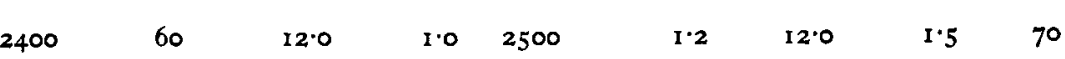

$\begin{array}{lllllllll}94.8 & 109.7 & 106.7 & 107.8 & 113.1 & 99.2 & 84.0 & 107.0 & 208.6\end{array}$

$\begin{array}{lllllllll}2400 & 55 & 12.0 & 0.55 & 1000 & 0.75 & 7.5 & \text { I.I } & 30\end{array}$

$\begin{array}{lllllllll}94.8 & 119.6 & 106 \cdot 7 & 196 \cdot 0 & 282 \cdot 7 & 159^{\circ} \cdot 1 & 134.4 & 145 \cdot 8 & 486.7\end{array}$

Subject B

work and travelling

Mean intake in I3 weeks, as

percentage of standard

N.R.C. standard for seden- 2400

tary man

Mean intake in 13 weeks, as $\quad 128.7$ percentage of standard

C.C.N. standard for seden- 2925

tary man, $200 \mathrm{lb}$.

Mean intake in 13 weeks, as 105.6 percentage of standard

C.C.N. standard for seden- 3145

tary man, $220 \mathrm{lb}$.

Mean intake in 13 weeks, as $\quad 98.2$ percentage of standard

The following figures compare the measured value with values calculated according to various formulas:

$\begin{array}{lc}\text { Measured } \quad \text { Method of determination } & \text { Cal./24 h } \\ \text { Calculated according to: } & 1300 \\ \text { Aub \& DuBois (1917) } & 1514 \\ \text { Harris \& Benedict (1919) } & 1392 \\ \text { Dreyer (1920) (actual weight) } & 1356 \\ \text { Dreyer (1920) (ideal weight) } & 1452 \\ \text { Dreyer (1920) (trunk height, weight) } & 1490 \\ \text { Food and Agriculture Organization of the United Nations: Committee on Calorie } & 1420 \\ \text { Conversion Factors and Food Composition Tables (1947) } & 1399 \\ \text { Robertson \& Reid (1952) } & \end{array}$

The measured basal metabolism was less than calculated values by amounts ranging from $4 \%$ for the Dreyer (actual weight) standard to $14 \%$ according to the Aub \& DuBois standard. 
Robertson (personal communication) states that these differences are all well within the range of his normal controls for each standard employed.

Since Robertson finds many values lower than that of subject $A$ in the mean heat output of women of similar age, it is probable that the caloric intake of many British women falls below calculated standards. This difference may explain the apparent inadequacy of the caloric intake of two subjects in the survey made by Yudkin (195 I), where the total energy intake was compared with basal metabolism calculated according to an unspecified formula.

The mean daily intake of subject A was $2275 \mathrm{Cal}$, which is $75 \%$ above the measured basal metabolism. This is a larger percentage than any quoted by Yudkin, and it should ensure adequate energy for all the activities undertaken.

The average daily intake was Ior \% of British Medical Association standards for women of $56 \mathrm{~kg}$ weight engaged in light work and travelling. It is reasonable to assume that this intake was sufficient, since health remained good and body-weight did not change by more than $1.96 \mathrm{~kg}$ in 18 months and remained constant for 2 years and 9 months after the conclusion of the experiment. The body-weight, however, was $6 \mathrm{I} \mathrm{kg}$, which suggests either that the standard is excessive for a woman weighing less, or that the slightly lower than average basal metabolic rate reduced the total requirement. It may be that this observation merely exemplifies the fact that individual requirements differ from that suggested for a group of persons of similar age, sex and activity.

By interpolation, the Canadian Council on Nutrition value for a sedentary woman of I34 lb. would be almost exactly the actual intake of $2275 \mathrm{Cal}$.

By applying the Food and Agriculture Organization: Committee on Calorie Requirements (1950) formula for estimating caloric requirements of women of varying weights:

$$
0 \cdot 9 E=82 \cdot 5(W)^{0.73}+7 \cdot 25 W+153
$$

(where $E=$ energy requirement and $W=$ body-weight in $\mathrm{kg}$ ), and correcting this estimate for the suggested reduction in energy expenditure in the basal metabolic and 'resting' states which occur after the early twenties, the estimated daily expenditure becomes $23 \mathrm{I} 6 \mathrm{Cal}$. This value is $\mathrm{I} \cdot 8 \%$ more than the recorded intake.

Weekly variations in body-weight and caloric intake were examined; there was no apparent relationship between them.

Subject $B$. The basal metabolism of this subject was not measured. It has been calculated by means of the standards of Robertson \& Reid (1952), which allow for a reduction in basal metabolism due to age. The value thus obtained is $1789 \mathrm{Cal} / 24 \mathrm{~h}$. The mean daily intake of $3089 \mathrm{Cal}$. is $72.6 \%$ above this basal metabolic rate.

By the Harris-Benedict formula, basal metabolism becomes 1965 Cal., leaving I 24 Cal. for activity, or $57 \%$ of basal needs.

Allowances recommended by the B.M.A. and the (U.S.A.) National Research Council for energy do not take account of overweight persons. The recorded intake was $112.3 \%$ of the B.M.A. standard for sedentary males and $128.7 \%$ of the N.R.C. standard. Any consideration of the apparent adequacy of this intake must take into 
account the weight and age of this subject and the fact that he was more active than a sedentary person.

The C.C.N., making allowance for increased body-weight, suggests $3145 \mathrm{Cal} /$ /day for a sedentary man of $220 \mathrm{lb}$. weight, which is $1.8 \%$ more than the average daily intake of subject $B$.

Application of the F.A.O. formula

$$
\circ .9 E=92 \cdot \circ(W)^{0.73}+{ }_{10} 0.88 W+236,
$$

and correction of this estimate for age, gives a daily expenditure of energy of this subject of $3 \mathrm{I}_{7} \mathrm{C}$ Cal. or $0.9 \%$ in excess of recorded intake. Since the subject remained well and neither gained nor lost weight, it is suggested that his caloric intake was just sufficient for his needs.

It is interesting that the caloric intake of both subjects came close to recommendations in which allowance is made for age as well as for sex and body-weight. Without the allowance for age and weight, the energy intake of subject $B$ differed appreciably from the standards.

\section{Nutrients}

An intake of nutrients exceeding the normal requirement is usually recommended to provide a surplus 'for safety'. Nutrients not required for the maintenance of health are metabolized, excreted or stored in the body.

Subject $A$. The mean daily intake was $100 \%$ or more of the B.M.A. recommended allowance over 70 weeks. Compared with N.R.C. standards, which are higher for many nutrients, the picture is almost as favourable, although the intake of nicotinic acid was suboptimal in both parts of the study $(82.8 \%$ in the $6 \mathrm{I}$-week study and $92 \cdot 6 \%$ in the 9 -week study).

An allowance for additional body-weight is made in Canadian tables, but the allowances recommended do not include a margin for safety. For all nutrients, the intake in this survey exceeded C.C.N. standards.

Despite the semi-vegetarian nature of this diet, there were 36 weeks in which protein intake exceeded the B.M.A. standard and a further 32 weeks in which it was more than $90 \%$ of this standard. The percentage of total protein from animal sources was never less than $4 \mathrm{I}$.

There were weeks in which caloric and nutrient intakes all reached or exceeded $100 \%$ (when intakes of fish and milk were generous), and others in which calcium, thiamine and vitamins $\mathrm{A}$ and $\mathrm{C}$ were the only nutrients to reach the B.M.A. standard. Nevertheless, the mean intake of these nutrients in the whole survey and in both parts was adequate by this standard. Furthermore, in 24 weeks, the intake of iron was suboptimal according to all three standards, and yet the mean daily intake in the whole survey was $107 \%$ of the suggested allowance. These examples emphasize the fallibility of a 7-day survey when an assessment of average nutrient intake is sought.

Subject $B$. The mean daily intake of all nutrients in this 13 -week survey exceeded the three dietary standards. 
Vitamin C intakes ranging from $139 \%$ (N.R.C.) to $520 \%$ (B.M.A.) were noteworthy because subject $\mathrm{B}$ ate little fresh fruit and relied largely on potatoes and, to a lesser extent, other cooked vegetables, for this vitamin. The vitamin A standard suggested by the C.C.N. is 1650 i.u., which is less than the mean intake (2700 i.u.) of preformed vitamin A of subject B.

The dietary needs of older age groups are thought to call for additional amounts of vitamins of the B complex, protein and calcium, and the (U.S.A.) National Research Council (1948) recommends 'small amounts' of vitamin D. The mean intake of subject $B$ appears satisfactory in the light of these requirements.

Differences in intake from one week to another were not as large as in the 70-week study of subject A. For 4 of the 13 weeks, vitamin $A$ intakes were low, ranging from 70.5 to $91.8 \%$, but the mean intake in 13 weeks was $124 \%$ of the B.M.A. standard. Similarly, the riboflavin intake was less than $100 \%$ in 7 weeks but $103.5 \%$ for the survey as a whole.

Conclusion. Comparison of diets in this survey with recommended allowances shows that adequate nutrition can be achieved by means of very different basic food patterns. The satisfactory intake of nutrients by subject $A$ was due to liberal amounts of milk, fish, fruit and vegetables, and for subject B it was due to cheese, bread and meat.

\section{Separate parts of the 70-week survey}

The 70-week survey was made up of two separate studies of unequal duration. When the experiment was planned it was intended that comparison should be made between mean intakes in these two studies, to determine whether an interval of freedom from weighing would alter the amounts of foods consumed. Any unconscious changes in dietary habits that might have occurred in the first part of the study should have disappeared after 3 months if the new habits were to be abandoned at all. Since the experiment involved no special diet and, therefore, no deliberate changes in normal food habits, no particular adjustments were foreseen.

Two changes that occurred during the survey period invalidate conclusions drawn from the effect of 3 months' liberty. One was a deliberate reduction in potato consumption which took place gradually from week 42 onwards. It was undertaken because the subject felt that the former consumption was excessive. The second was a severe curtailment of smoking in the interval between the two parts of the study. Subject A was of the opinion that the sole result of the smaller intake of potato was an increase in the amount of green and other vegetables eaten at that meal. When smoking was curtailed, the subject craved an alternative habit, and eating fruit appeared to satisfy this craving. She thought her consumption of raw fruit rose immediately that of cigarettes fell.

Neither of these changes was foreseen when the experiment began, but long-range changes of this kind may occur in any régime. Thus, in spite of these changes comparison has been made between the two studies.

Caloric intake and body-zweight. In both parts of the survey the mean daily caloric intake was the same; the average body-weight was $6 \mathrm{r} \mathrm{kg}$, i.e. $6 \mathrm{r} .07 \mathrm{~kg}$ in part $\mathrm{I}$ and $60.67 \mathrm{~kg}$ in part 2. 
Weight of food eaten. The average weight of food eaten each day in the longer survey was $62 \cdot 2 \mathrm{oz}$. In the shorter one it was $64 \cdot 6 \mathrm{oz}$., the additional weight consisting largely of fruit, root and green vegetables and salad plants. The intake of other foods was almost identical. It is interesting to find that the amount of 'visible' fat consumed fell by $0.2 \mathrm{oz} .(5.7 \mathrm{~g})$ daily, and yet the average daily intake of fat in the $6 \mathrm{I}$-week study was $87.4 \mathrm{~g}$ and in the 9 -week study was $89.9 \mathrm{~g}$. The increase was obviously due to food fat obtained from bacon, cheese and canned oily fish.

Nutrient intake. The intake of nutrients other than vitamin D and carbohydrates was slightly larger in the 9-week survey than in the $6 \mathrm{I}$-week one. The intake of vitamin $\mathrm{D}$ fell by 32 i.u. and that of carbohydrate by $8 \cdot 5 \mathrm{~g}$.

Additional fruit and also root and green vegetables used to replace potatoes in the diet undoubtedly led to an increased intake of vitamins $A$ and $C$ and members of the $B$ complex.

The effect of a reduced consumption of potatoes. The mean daily intake of carbohydrate in the first 6r weeks was $306.9 \mathrm{~g}$ and in the 9-week study it was $298.4 \mathrm{~g}$. The smaller intake of carbohydrate in the 9 -week study can be explained by the reduced consumption of potatoes. The mean daily intakes of carbohydrate and calories were:

\begin{tabular}{|c|c|c|}
\hline & $\begin{array}{l}\text { Carbohydrate } \\
\text { (g) }\end{array}$ & $\begin{array}{c}\text { Calories } \\
\text { (Cal.) }\end{array}$ \\
\hline Weeks I-42 & $3 \mathrm{II} \cdot 6$ & 2284 \\
\hline $\begin{array}{l}\text { Weeks } 43-63 \\
\text { Weeks } 77-85\end{array}$ & $\left.\begin{array}{l}297.2 \\
298.4\end{array}\right\}$ mean 297.8 & $\left.\begin{array}{l}2257 \\
2274\end{array}\right\}$ mean 2267 \\
\hline
\end{tabular}

The mean daily caloric intake never exceeded 2500 Cal. after week 42.

Comparison of these two studies shows that caloric intake was identical in both and that average intakes of most nutrients were larger in the shorter study, generally by very small amounts. Having regard to alterations in dietary habits over a span of I 8 months these changes are readily explained, and it is remarkable that caloric and nutrient intake did not vary more.

\section{SUMMARY}

I. The diets consumed by two adults have been studied. One subject was a man aged 66 years whose study lasted for 13 consecutive weeks, the other subject was a woman aged 34 years whose study lasted for 6r weeks and later for another 9 weeks. The diets were weighed by each subject and the calories and nutrients in them calculated from food tables.

2. The weekly intake of calories and nutrients showed considerable variation. The extent of variability differed with the different dietary components and with the two subjects.

3. Estimates of the mean daily intake of the subject of the longer study, based on I week sampled at random within a year, had standard errors of $8-15 \%$ for most of the dietary components but much larger percentage standard errors for some vitamins. Since there is no reason to think that the dietary habits of this subject were particularly variable, this finding suggests that the results of short-term dietary surveys should be interpreted with caution. 
4. The advantage of taking observations for a single period longer than $I$ week appears to be rather small if an estimate of average nutrient intake over a year is required. A more accurate estimate will be obtained from a number of $\mathrm{I}$-week periods covering the year systematically than from a single sampling period of the same duration.

In this survey data for at least three I-week periods chosen systematically within the year were required in order to estimate the average intake of the least variable dietary constituents with standard errors of $\pm 5 \%$. Such a sample would estimate the mean intake of nine of the thirteen dietary components recorded with standard errors of $\pm 8 \%$ or less.

The author wishes to thank the Scientific Adviser's Division of the Ministry of Food for assistance with the conversion of food intake to nutrient intake; Dr J. Douglas Robertson for determining her basal metabolism; and Dr F. Yates, F.R.S. and Mr B. M. Church of the Rothamsted Experimental Station for statistical analysis of the results of this survey.

The details of the methods worked out for dealing with the present survey will be published separately (Church \& Lipton, 1956).

\section{REFERENCES}

Aub, J. C. \& DuBois, E. F. (1917). Arch. intern. Med. r9, 823 .

Bransby, E. R, Daubney, C. G. \& King, J. (1948-9a). Brit. F. Nutr. 2, 89.

Bransby, E. R., Daubney, C. G. \& King, J. (1948-9b). Brit. F. Nutr. 2, 232.

British Medical Association (1950). Report of the Committee on Nutrition. London: British Medical Association.

Canadian Council on Nutrition (1950). Canad. Bull. Nutr. 2, no. I.

Church, B. M. \& Lipton, S. (1956). Brit. $\mathcal{F}$. Nutr. ro. (In the Press.)

Dreyer, G. (1920). Lancet, 199, 289.

Food and Agriculture Organization of the United Nations: Committee on Calorie Conversion Factors and Food Composition Tables (1947). Energy-yielding Components of Food and Computation of Calorie Values. Washington, D.C.: Food and Agriculture Organization of the United Nations.

Food and Agriculture Organization of the United Nations: Committee on Calorie Requirements (r950). F.A.O. nutr. Stud. no. 5 .

Harris, J. A. \& Benedict, F. G. (1919). Publ. Carneg. Instn, no. 279.

Harris, L. J. \& Olliver, M. (I943). Lancet, 244, 454.

McCance, R. A. \& Widdowson, E. M. (1942). Spec. Rep. ser. med. Res. Coun., Lond., no. 235.

McHenry, E. W., Ferguson, H. P. \& Gurland, J. (1945). Canad. publ. Hlth F. 36, 355.

Medical Research Council: Accessory Food Factors Committee (1945). M.R.C. (War) Memor. no. 14.

National Research Council (1948). Repr. nat. Res. Coun., Wash., no. I29.

Roberts, P. H., Kerr, C. H. \& Ohlson, M. A. (1948). F. Amer. diet. Ass. 24, 292.

Robertson, J. D. \& Reid, D. D. (1952). Lancet, 262, 940.

Tigerstedt, R. (1916). Skand. Arch. Physiol. 34, 15 I.

United States Department of Agriculture (1945). Misc. Publ. U.S. Dep. Agric. no. 572.

Wait, B. \& Roberts, L. J. (1932). F. Amer. diet. Ass. 8, 323.

War Office, AMD 5 (I945). Nutritive Value of Foodstuffs. London: H.M. Stationery Office.

Widdowson, E. M. \& McCance, R. A. (1943). Lancet, 244, 230,

Widdowson, E. M. \& McCance, R. A. (1945). Proc. Nutr. Soc. 3, I 10.

Yudkin, J. (1951). Brit. F. Nutr. 5, 177. 